\title{
The Comprehensive Evaluation Algorithm with Fault Location in HVDC Transmission Line
}

\author{
Zhenquan Sun', Qiyue Huang², Changjin Hu${ }^{1}$, Xiaoning Kang2, Hao Wang2, Xuze Zhang2, \\ Chong Zhao' ${ }^{2}$, Yali $\mathrm{Ma}^{3}$ \\ ${ }^{1}$ Shaanxi Regional Electric Power Group Co., Ltd., Xi'an, China \\ ${ }^{2}$ Shaanxi Key Laboratory of Smart Grid (Xi'an Jiaotong University), Xi'an Jiaotong University, Xi'an, China \\ ${ }^{3}$ Tianjin Power Transmission and Transformation Engineering Company, Tianjin, China \\ Email: 839539199@qq.com
}

How to cite this paper: Sun, Z.Q., Huang, Q.Y., Hu, C.J., Kang, X.N., Wang, H., Zhang, X.Z., Zhao, C. and Ma, Y.L. (2017) The Comprehensive Evaluation Algorithm with Fault Location in HVDC Transmission Line. Energy and Power Engineering, 9, 30-35. https://doi.org/10.4236/epe.2017.94B004

Received: February 21, 2017

Accepted: March 30, 2017

Published: April 6, 2017

\begin{abstract}
China has a vast territory with a great demand for electricity. However, the resources are in reverse distribution in the country. Therefore, high voltage direct current transmission has great practical significance and been widely used. However, traditional fault location methods have a lot of problems in engineering application for the length of transmission line and the complexity of the terrain. This paper proposes a comprehensive evaluation algorithm based on the travelling wave method and time domain method. It also proposes a concept of fault point reliability. This algorithm analyzes the fault point reliability in the whole transmission line to determine the specific location of the fault point. This paper proves that the algorithm has high reliability by PSCAD simulation software.
\end{abstract}

\section{Keywords}

Comprehensive Evaluation Algorithm, Travelling Wave Method,

Time-Domain Method, Fault Location, Fault Point Reliability

\section{Introduction}

The development of power transmission technology has become faster than before since the 80 s in the last century. Plenty of methods to improve the transmission capacity are also emerging. Comparing to the traditional AC transmission, HVDC technology has high economic, technical and performance of transmission. The direct current transmission line has the characteristics of low cost, lost power consumption and narrow line corridor. It also has advantages of high speed of adjustment and reliability operation. Therefore, high direct current transmission technology has been applied and popularized in our country. 
These transmission systems have the advantages of high efficiency and high reliability, but they still have defects in practical application. At present, in addition to BTB project, the length of domestic DC transmission lines are more than $500 \mathrm{~km}$. At the same time, long distance transmission lines cross the forest, mountains, rivers and other complex terrain. Bad work environment and high fault rate will greatly increase the difficult of the fault line when the fault occurs, which seriously affects the recovery time of the permanent fault. The fault has less damage to the line itself for the development of relay protection technology. Local defects with no obvious changes in appearance bring serious difficulties to the fault investigation. Therefore, it can be seen that HVDC transmission line fault location technology research has great practical significance and demands [1] [2].

\section{Traditional Fault Location Method}

The traditional fault location method of high voltage direction current transmission line is divided into two kinds, the travelling wave method and the time domain method. Travelling wave method is an algorithm using the theory of travelling wave to determine the location of the fault point, which is based on high sampling rate data. This algorithm has advantages of high accuracy and be little influenced by the system operation mode and fault resistance. It is popular in fault location technology. The time domain method is an algorithm using the system parameters and the double ended data of the line to determine the location of the fault point, which is based on low sampling rate data. Comparing to the travelling wave method, this algorithm has low accuracy, but it has good reliability in data resources [3].

From the above we can know that the HVDC fault location technology has been widely used in practical project, but there are still a lot of problems in it. It has a huge space for improvement. The principles of traditional fault location are introduced.

\subsection{Travelling Wave Method in Fault Location}

At present, travelling wave method is widely used in HVDC transmission system. This method is an algorithm using the theory of travelling wave to determine the location of the fault point. Travelling wave methods are divided into six types according to data source selection and source differences. Although the travelling wave method's reliability and accuracy is higher than other methods, it still has some difficulties in the practical engineering. The travelling wave phenomenon of the line's voltage and current must be measured by the transformer. It is a problem to measure the travelling wave signal in an economic and simple method. The uncertainty of the travelling wave signal generated by the fault also restricts the development of the fault location technology. Although there are various kinds of problem in fault location method, the research on the new technology has never been stopped. 


\subsection{Time-Domain Method in Fault Location}

In addition to the travelling wave method, time domain method is used in fault location in HVDC system. HVDC transmission line has unstable power frequency which caused frequency domain method is replaced by time domain method in practical. This method is an algorithm to analysis and calculate the distance from the fault point, which is based on the system parameters and the value of current and voltage [4]. The criterion function is constructed as below:

$$
f(x, t)=\sum_{t_{1}}^{t_{t}}\left|u_{k}(x, t)-u_{m}(l-x, t)\right|
$$

Time domain method requires actual recorded data which is reliable. It can calculate the distance by the sampling point and becomes a new trend of modern transmission line fault location. In spite of this, there are still a lot of shortcomings in the practical application. Formula (3) shows that the parameters of line and velocity of wave are key factors which caused the accuracy of calculation. Comparing to $\mathrm{AC}$ lines, the parameters of DC lines are always not accurate. This phenomenon is more obvious with the increase length of DC transmission lines. At present, the application of time domain method in HVDC system is still in an initialstage [5] [6].

\section{Comprehensive Evaluation Algorithm}

It can be known that the traditional fault location method has been widely used in practical project. This paper proposes a new comprehensive assessment algorithm based on these methods. The comprehensive algorithm creatively combines travelling wave method with time domain method. It determines the fault point reliability by analyzing each point along the high voltage direct current transmission lines. Fault location is performed by selecting the highest reliability along the line. This comprehensive method combines the advantages of travelling wave method with time-domain method. It effectively avoids the disadvantages of traditional algorithm. It has high reliability and accuracy [7].

\subsection{Fault Point Reliability}

This paper proposes the conception of fault point reliability, aiming to analyze the possibility of each point along the line to be the point of fault, to measure the location of fault. Travelling wave location method calculates a result named $\mathrm{L}$. The point at which the distance from the measuring point is $\mathrm{L}$ can be regarded as the fault point. This point's fault point reliability is $100 \%$ and other points' reliability is $0 \%$. In practical project and PSCAD simulation, there are some errors in the traditional distance location methods. It can be seen that, in addition to ideal fault point has the possibility of being actual fault point, points near the ideal point also has possibility. The figure is presented to determine the fault point reliability which is in the vicinity of ideal fault point.

Point $\mathrm{A}$ is the ideal fault point in Figure 1. It can be concluded that the fault reliability is satisfied with the Gaussian distribution. Each point along the whole 


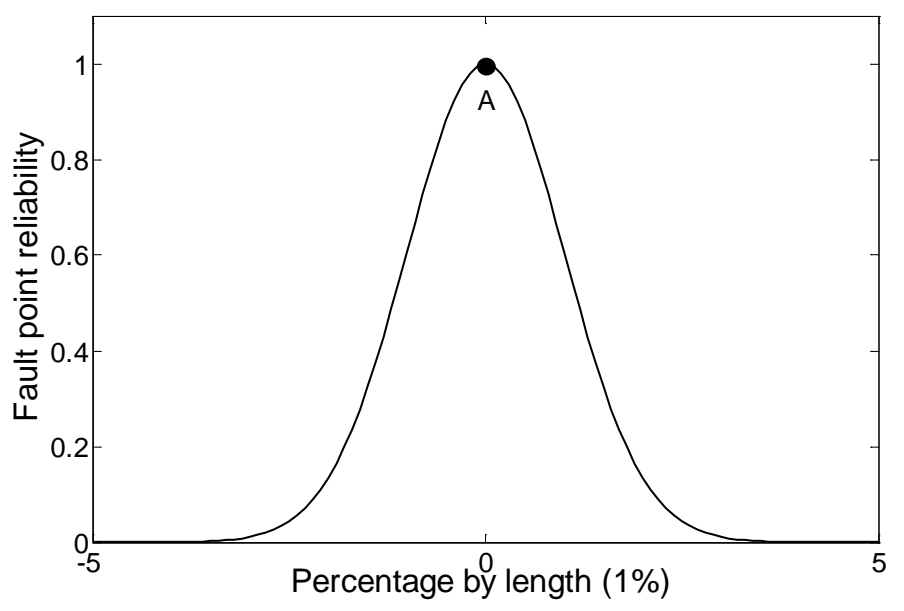

Figure 1. Gaussian distribution of fault point reliability.

line has corresponding fault point reliability. This plan satisfies actual model and reduces the defects of the measurement error in a certain extent.

\subsection{The Principle of Comprehensive Evaluation Algorithm}

This paper introduces the basic concept of the fault point reliability. The results of this method and traditional methods are the same when only one location method is used in comprehensive method. It still has traditional defects. The principle of comprehensive evaluation algorithm is combing traditional method and using fault point reliability to calculate fault location. This algorithm calculates the sum of the results measured by traditional methods in a certain weight. It calculates integrated fault point reliability and determines the location of fault point. The calculation formula is as below:

$$
\begin{gathered}
S_{x}=\frac{A \times S_{A}+B \times S_{B}}{2} \quad \mathrm{x} \in(0, L) \\
A=A_{1}+A_{2}+A_{3}+\cdots \cdots \quad B=B_{1}+B_{2}+B_{3}+\cdots \cdots
\end{gathered}
$$

In these formulas: $S_{A}$ is the fault point reliability calculated by travelling wave method; $S_{B}$ is the fault point reliability calculated by time-domain method; $S_{X}$ is the integrated fault point reliability which is $\mathrm{x}$ meter away from measurement end; $L$ is the length of line. $A$ is the weight of travelling wave method; $B$ is the weight of time-domain method; $A_{1}, A_{2}, A_{3}, B_{1}, B_{2}, B_{3}$ are weight factors; $A_{1}=B_{1}=$ 1; $A_{1}, A_{2}$ are initial weight factors; the other weight factors' value depends on practical situation. This method determines the location of fault points by comparing the overall fault point reliability along the line.

Formula (2)-(3) shows that comprehensive evaluation algorithm is equivalent to the simple sum of traditional methods when they are normal. This algorithm can change traditional weights in it by changing the weight factors to reduce adverse effect when traditional methods in fault. It greatly increases the accuracy and reliability of fault location method. The block diagram of comprehensive evaluation algorithm is shown as below (Figure 2): 


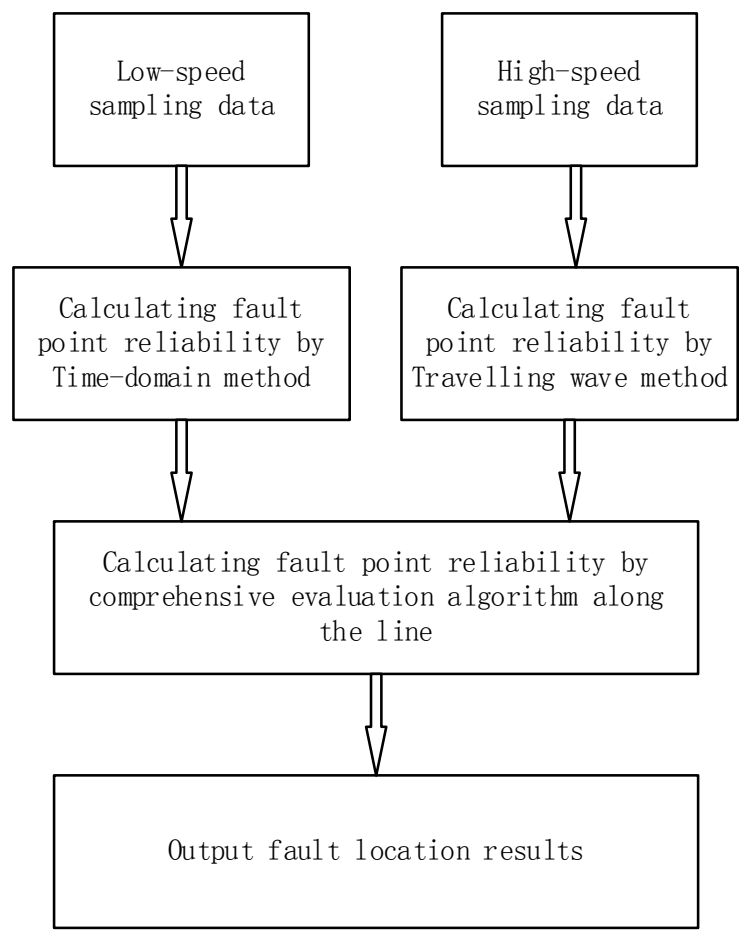

Figure 2. The block diagram of comprehensive evaluation algorithm.

\section{Simulation and Experimental Results}

The PSCAD/EMTDC simulation tool is used to construct a 500-kV HVDC transmission system model. The DC transmission line is built by Bergeron Model. The reliability of travelling wave method is low because of the high resistance grounding. The converter frequently turned on/off brought a large number of interference which affects the accurate identification of the reflected wave. There will be plenty of false results by using travelling wave method. The weight of travelling wave method in comprehensive algorithm is reduced. Assuming that $A_{2}=-0.5$. The simulation's results are showed as below:

As can be seen from the above table, this algorithm has high reliability and accuracy. It proposes the conception of fault point reliability. It combines the travelling wave method with time-domain method and overcomes the shortcomings of traditional method. The system fault distance is calculated by measuring the highest fault point reliability along the line.

\section{Conclusion}

In this paper, the principle of HVDC transmission line fault location is introduced in detail. Traditional location methods' advantages and disadvantages are showed in practical project. Analyzing domestic and foreign well-known scholars' study on fault location, the existing fault location methods have plenty of problems: low accuracy, low reliability and high sampling rate. These shortcomings greatly influence the application of fault location in high voltage system. This paper creatively put forward a new concept of fault point reliability. It 
Table 1. Results of simulation.

\begin{tabular}{cccc}
\hline Ideal fault location & $\begin{array}{c}\text { Travelling wave } \\
\text { method location }\end{array}$ & $\begin{array}{c}\text { Time-domain } \\
\text { method location }\end{array}$ & $\begin{array}{c}\text { Comprehensive } \\
\text { evaluation method } \\
\text { location }\end{array}$ \\
\hline $100 \mathrm{~km}$ & $100 \& 127 \& 421 \mathrm{~km}$ & $100 \mathrm{~km}$ & $100 \mathrm{~km}$ \\
$500 \mathrm{~km}$ & $500 \& 721 \& 1107 \mathrm{~km}$ & $494 \mathrm{~km}$ & $500 \mathrm{~km}$ \\
$900 \mathrm{~km}$ & $462 \& 900 \mathrm{~km}$ & $885 \mathrm{~km}$ & $896 \mathrm{~km}$ \\
$1300 \mathrm{~km}$ & $571 \& 1300 \& 1590 \mathrm{~km}$ & $1278 \mathrm{~km}$ & $1295 \mathrm{~km}$ \\
$1700 \mathrm{~km}$ & $910 \& 1700 \mathrm{~km}$ & $1669 \mathrm{~km}$ & $1690 \mathrm{~km}$ \\
\hline
\end{tabular}

proposes a comprehensive evaluation algorithm, based on travelling wave method and time-domain method, to measure the fault location (Table 1). This algorithm combines the travelling wave method with time-domain method and overcomes the shortcomings of traditional method. The simulation of PSCAD software shows that the comprehensive evaluation method has high accuracy and reliability. It can measure fault location in any case. It has good economic performance because the system doesn't need to increase any device on the transmission line. It can be concluded that this algorithm has good application ability and research potential.

\section{References}

[1] Ge, Y.Z. (2007) New Types of Protective Relaying And Fault Locate on Their Theory and Techniques. 2nd Edition, Xi'an Jiaotong University Press, Xi'an.

[2] Song, G.B., Zhou, D.S., Jiao, Z.B., et al. (2007) A Novel Fault Location Principle for HVDC Transmissionline. Automation of Electric Power Systems, 31, 57-61.

[3] Xing, L.H. Research on Protection and Fault Location Principles for HVDC Transmission Lines. Shan Dong University, Jinan.

[4] (2012) Survey of fault location research for HVDC transmission lines. Power System Protection and Control, 40, 133-137.

[5] Liang, Y.S., Wang, G., and Li, H.F. (2013) Time-Domain Fault-Location Method on HVDC Transmission Lines Under Unsynchronized Two-End Measurement and Uncertain Line Parameters. IEEE Transactions on Power Delivery.

[6] Song, G.B., Suo, N., Jia, L. and Xu, Q.Q. (2004) A Novel Time-Domain Algorithm for Location Faults on Parallel Transmission Lines by Circulating Circuit. Proceeding of CSEE, 24, 24-29.

[7] Xu, M., Cai, Z.X. and Liu, Y.H. (2012) Mechanism and Improvement of Errors in Travelling Wave Fault Location of DC Transmission Line. Guangdong Electrical Power, 25, 40-45. 
Submit or recommend next manuscript to SCIRP and we will provide best service for you:

Accepting pre-submission inquiries through Email, Facebook, LinkedIn, Twitter, etc. A wide selection of journals (inclusive of 9 subjects, more than 200 journals)

Providing 24-hour high-quality service

User-friendly online submission system

Fair and swift peer-review system

Efficient typesetting and proofreading procedure

Display of the result of downloads and visits, as well as the number of cited articles Maximum dissemination of your research work

Submit your manuscript at: http://papersubmission.scirp.org/

Or contact epe@scirp.org 